\title{
Is there a conflict between general practitioners applying guidelines for antibiotic prescribing and including their patients' preferences?
}

This article was published in the following Dove Press journal:

Patient Preference and Adherence

\author{
Anne EM Brabers' \\ Thamar EM Van Esch' \\ Peter P Groenewegen ${ }^{1-3}$ \\ Karin Hek' \\ Pé Mullenders ${ }^{4}$ \\ Liset Van Dijk' \\ Judith D De Jong' \\ 'NIVEL, the Netherlands Institute for \\ Health Services Research, Utrecht, \\ ${ }^{2}$ Department of Sociology, Utrecht \\ University, Utrecht, ${ }^{3}$ Department of \\ Human Geography, Utrecht University, \\ Utrecht, ${ }^{4}$ The National Health Care \\ Institute, Diemen, the Netherlands
}

Correspondence: Anne EM Brabers NIVEL, the Netherlands Institute for Health Services Research, Otterstraat I I8-I24, 35 I 3 CR Utrecht, Utrecht, the Netherlands

$\mathrm{Tel}+3 \mid 302729700$

Fax +31 302729729

Email a.brabers@nivel.nl
Objectives: One perceived barrier to guideline adherence is the existence of conflicting patient preferences. We examined whether patient preferences influence the prescription of antibiotics in general practice, and how this affects guideline adherence. We hypothesized that preferences play a larger role in prescribing antibiotics if the guideline allows for preferences to be taken into account, ie, if prescribing antibiotics is an option which can be considered rather than a clear recommendation to prescribe or not. We included three guidelines: acute cough, acute rhinosinusitis, and urinary tract infections.

Methods: Data from NIVEL (the Netherlands Institute for Health Services Research) Primary Care Database (NIVEL-PCD) were used to assess antibiotic indications and prescriptions. These data were combined with a questionnaire among members of NIVEL's Dutch Health Care Consumer Panel to examine patient preferences. According to NIVEL-PCD, 286 of these members contacted their general practitioner (GP) in 2015 for acute cough, acute rhinosinusitis or urinary tract infections. A logistic multilevel regression analysis was performed to test our hypothesis.

Results: Patient preferences do play a role in GPs' prescribing of antibiotics only in situations where, in accordance with the guideline, their use is an option which could be considered (interaction between indication and preference: $p=0.049$ ). If patients ask for antibiotics themselves in such situations, then GPs prescribe antibiotics more often.

Conclusion: Patient preferences only play a role if the guideline provides room to take preferences into account. Therefore, our results do not suggest a conflict between applying guidelines and including patient preferences. Further research is recommended to examine this possible conflict in other situations.

Keywords: antibiotics, clinical practice guidelines, medical practice variation, patient preferences

\section{Introduction}

Clinical practice guidelines give recommendations about appropriate health care As such they have the potential to reduce inappropriate practice variation, enhance the translation of research into practice, and maintain and improve health care quality and safety. ${ }^{1-4}$ The extent to which physicians adhere to guidelines can be regarded as an indicator of the quality of care delivered. ${ }^{5}$ Adherence to guidelines varies considerably, both between physicians and practices and between different guidelines. ${ }^{6-10}$ One perceived barrier to adherence to guidelines, mentioned by physicians, is the existence of patient preferences. ${ }^{11}$ Yet, another key indicator of good quality of care is providing care that is respectful of, and responsive to, an individual patient's preferences, needs, 
and values. ${ }^{12}$ This requires that patient preferences are incorporated into the decision-making process.

In theory, the decision-making process involves physicians bringing in the recommendations of the guideline and the clinically relevant characteristics of their patients, while the patients bring in their preferences. In making medical decisions, there might, however, be a conflict between applying these guidelines and including patient preferences. ${ }^{13,14}$

An area where adherence to guidelines can be improved is in the prescription of antibiotics. Wide variations exist in the rates of antibiotic prescribing. ${ }^{15-17}$ Inappropriate prescribing of antibiotics is directly related to higher rates of antimicrobial resistance. ${ }^{17-19}$ This is now globally recognized as a major threat to human health..$^{20,21}$ The Netherlands, the setting of this study, has comparatively low and stable antibiotic use in primary care. ${ }^{17,22}$ Still, there are large variations among Dutch general practitioners (GPs) in the adherence to guidelines when prescribing antibiotics. ${ }^{7-9,23}$ These guidelines are developed by the Dutch College of General Practitioners (NHG). The NHG strives to ensure that its guidelines are widely accepted. This is encouraged by involving GPs in the development process (Box 1). This study focuses on the prescription of antibiotics by Dutch GPs for three conditions for which guidelines were published more than 10 years ago and which were recently updated: 1) acute cough, last version 2013; 2) acute rhinosinusitis, last version 2014; and 3) urinary tract infections, last version 2013. These guidelines were chosen for two reasons. Firstly, wide variations in antibiotic prescribing rates have been observed in the Netherlands for these conditions..$^{24,25}$ Secondly, they involve different recommendations about the prescription of antibiotics. These recommendations range from an indication for antibiotics, to an "unsure" indication for antibiotics that is that antibiotics may be considered by the GP - to no indication for antibiotics. For example, for both acute cough

The Dutch College of General Practitioners (NHG) develops guidelines for GPs. It selects a topic for which a guideline should be formulated. A working group, mainly consisting of GPs, develops the guideline using a predetermined procedure. Comments are made about this concept guideline in two phases, one internal and one external round. After the guideline is revised, it is sent to the appropriate NHG committee for authorization. As a final step, the NHG publishes the guideline on the NHG website and in the Dutch journal for GPs "Huisarts \& Wetenschap" ${ }^{47}$ The first guideline appeared in 1989 and around 100 guidelines for different diagnoses are currently available. ${ }^{48}$

Box I Procedure to develop guidelines for GPs in the Netherlands.

Abbreviations: GP, general practitioner; NHG, Dutch College of General Practitioners. and rhinosinusitis antibiotics are generally not indicated in otherwise healthy patients, whereas antibiotics can be considered in vulnerable groups such as people aged over 75 . For healthy women with a urinary tract infection antibiotics may be considered, while antibiotics are always indicated for men with urinary tract infection. Extensive recommendations are shown in Table 1.

Patient expectations, as well as patient demand or "pressure", have been mentioned by GPs as major factors in the decision to prescribe antibiotics and are associated with increased antibiotic prescribing. ${ }^{26-30}$ Patient expectations can be defined as the patient's perception of what their GP might do in a specific situation. Expectations differ from hoping for, or preferring, an antibiotic prescription and from explicitly expressing the hope, or preference, for an antibiotic - ie, asking for an antibiotic prescription. ${ }^{30}$ In addition, patients might explicitly express a preference not to be given a prescription for an antibiotic. Yet, few studies have examined the direct relationship between patient expectations or preferences on the one hand, and the GP's decision to prescribe antibiotics on the other.$^{30}$ For instance, Coenen et al found that both patient expectation and hope were positively associated with antibiotic prescribing by GPs for acute cough. ${ }^{30}$ The present study aims to examine further the relationship between patient preferences and the GP's decision to prescribe an antibiotic. By examining this, we aim to achieve further insight into the possible conflict between applying guidelines and including patient preferences in decision-making. We answer the following research question: Do patient preferences influence the GP's decision to prescribe antibiotics, and how does this affect adherence to guidelines by GPs? We hypothesize that patient preferences have a larger role in the GP's decision to prescribe an antibiotic if the guideline provides room to take patient preferences into account. In other words, if the prescribing of antibiotics is an option which can be considered - that is an "unsure" indication - rather than a clear recommendation to prescribe or not.

\section{Materials and methods}

\section{Study design}

To answer our research question, we used a combined set of data from the NIVEL (the Netherlands Institute for Health Services Research) Primary Care Database (NIVEL-PCD) and data from the Dutch Health Care Consumer Panel of NIVEL. Data from NIVEL-PCD were used to assess the GP's prescription of antibiotics. A questionnaire among members of the Dutch Health Care Consumer Panel of NIVEL was conducted in order to examine patient preferences for antibiotics. 
Table I Recommendations about the prescribing of antibiotics for the guidelines acute cough, acute rhinosinusitis, and urinary tract infections

\begin{tabular}{|c|c|c|}
\hline Guideline & $\begin{array}{l}\text { Acute cough, } \\
\text { last version } 2013^{49}\end{array}$ & $\begin{array}{l}\text { Acute rhinosinusitis, } \\
\text { last version } 2014^{50}\end{array}$ \\
\hline Diagnoses (ICPC) & $\begin{array}{l}\text { Acute cough (R05), Whooping } \\
\text { cough (R7I), Laryngitis/tracheitis } \\
\text { acute (R77), Acute bronchitis/ } \\
\text { bronchiolitis (R78) }\end{array}$ & $\begin{array}{l}\text { Sinus symptom/complaint (R09), } \\
\text { Upper respiratory infection acute } \\
\text { (R74), Sinusitis acute/chronic (R75) }\end{array}$ \\
\hline $\begin{array}{l}\text { Antibiotics } \\
\text { recommendations } \\
\text { in guideline }\end{array}$ & $\begin{array}{l}\text { No antibiotics if pneumonia is } \\
\text { not considered likely. Exceptions } \\
\text { in which antibiotics should be } \\
\text { considered are patients with one or } \\
\text { more risk factors: } \\
\text { - Age }<3 \text { months or }>75 \text { years } \\
\text { - Relevant comorbidity: heart } \\
\text { failure, severe COPD, diabetes } \\
\text { mellitus (in particular when using } \\
\text { insulin), neurological diseases, } \\
\text { severe kidney diseases } \\
\text { - Poor immune response CRP in } \\
\text { adults: }<20 \text { mg/L no indication } \\
\text { for antibiotics, } 20-100 \text { mg/L } \\
\text { indication for antibiotics depends } \\
\text { on the clinical presentation, } \\
>I 00 \text { mg/L indication for } \\
\text { antibiotics }\end{array}$ & $\begin{array}{l}\text { In principle, no antibiotics. } \\
\text { Antibiotics are indicated in patients } \\
\text { who are seriously ill. Antibiotics } \\
\text { can be considered in patients with } \\
\text { poor immune response: } \\
\text { - Chronic use of corticosteroids } \\
\text { or other immunosuppressive } \\
\text { medicines } \\
\text { - HIV infection with a reduced } \\
\text { number of T-cells } \\
\text { - Chemotherapy or radiotherapy } \\
\text { - Immune disorders } \\
\text { - Frail elderly who are sick } \\
\text { - Patients with diabetes mellitus } \\
\text { Antibiotics can be considered for } \\
\text { patients who have had fever for } \\
\text { more than } 5 \text { days, or for patients } \\
\text { who have recurrent fever after } \\
\text { a few fever-free days within one } \\
\text { episode of rhinosinusitis }\end{array}$ \\
\hline
\end{tabular}

Antibiotics not indicated...

Antibiotics can be considered...

Antibiotics are indicated...
In patients with cough (R05, R77, R78) between 18 and 75 years, without indications for poor immune response, ${ }^{\text {a }}$ with CRP $<20$ and without relevant comorbidity In patients with cough (R05, R77, R78) over 75 years, or with indications for poor immune response, or with CRP $>20$ or with relevant comorbidity and in patients with whooping cough (R7I) In patients with cough (R05, R77, R78) and CRP $>100$
In patients with sinus complaints (R09, R74, R75) without indications for poor immune response

In patients with sinus complaints (R09, R74, R75) with an indication for poor immune response

In patients with sinus complaints (R09, R74, R75) and CRP $>100$

\author{
Urinary tract infections, \\ last version $2013^{51}$ \\ Dysuria/painful urination ( $\mathrm{U} 0 \mathrm{I})$, \\ Urinary frequency/urgency (U02), \\ Cystitis/urinary tract infection (U7I)
}

- Healthy women aged 12 years and older who are not pregnant: the GP [...] discusses the possibility of wait and see $[\ldots]$ and a postponed antibiotics prescription

- Recurrent cystitis in healthy women ( 12 years and older) who are not pregnant: [...] (three or more yearly) the following options: self-treatment with a postponed antibiotics prescription, or prophylactic treatment with [...] continuous antibiotic prophylaxis

- Cystitis in risk groups: patients in risk groups have an increased risk for complications of cystitis. In those patients, cystitis should be treated with antibiotics, in anticipation of the test results. Risk groups include: pregnant women, men, patients with diabetes mellitus, patients with poor immune response, and patients with abnormalities of the kidneys or urinary tract

- Urinary tract infection with signs of tissue invasion: explain [...] that antibiotic treatment is necessary $[\ldots]$ In patients with urinary complaints (U0I, U02)

In healthy women, who are not pregnant, with urinary tract infection (U7I) without abnormalities of the kidneys or urinary tract and without indications for poor immune response

In patients with urinary tract infection (U7I) who are male, or pregnant, or have abnormalities of the kidneys or urinary tract, or indications for poor immune response

Signs of tissue invasion cannot be retrieved from NIVEL Primary Care Database and are consequently not taken into account. No distinction between a single bout of cystitis or recurrent cystitis is made, because in both cases antibiotics can be considered in healthy women who are not pregnant

Notes: apatients are considered as having a poor immune response if at least one of the following drugs were prescribed: corticosteroids (chronic use), cytostatic drugs, DMARDs, biologicals, anti-thyroid drugs, phenytoin, neuroleptics, antivirals for systemic use, or if at least one of the following diseases was recorded: HIV infection, cancer, diabetes mellitus, severe alcohol abuse, sickle cell disease, (functional) asplenic, severe renal insufficiency.

Abbreviations: ICPC, International Classification of Primary Care; GP, general practitioner; DMARDs, disease-modifying antirheumatic drugs; NIVEL, Netherlands Institute for Health Services Research. 
All the members of the consumer panel included are registered patients of 15 general practices which participate in the NIVEL-PCD. As such, we were able to combine, at the patient level, the GP's prescription of antibiotics with patient preferences for antibiotics.

\section{NIVEL-PCD}

NIVEL-PCD collects, over time, data from the routine electronic health records of a large and dynamic pool of general practices across the Netherlands. ${ }^{31}$ These data comprise information on consultations, morbidity, and prescriptions. Morbidity is registered using the International Classification of Primary Care version 1 (ICPC-codes) $)^{32,33}$ in constructed illness episodes. ${ }^{34}$ Prescription data are classified according to the Anatomical Therapeutic and Chemical (ATC) classification. We used data from 2015.

\section{Dutch Health Care Consumer Panel}

The Dutch Health Care Consumer Panel aims to measure the attitude toward, and the knowledge of, health care as well as the expectations and experiences of health care among a cross-section of the Dutch population. ${ }^{35}$ All 2,816 panel members selected for this study were recruited via the previously mentioned 15 general practices participating in the NIVELPCD. The panel members selected received a questionnaire about antibiotics early in March 2016. According to their previously stated preference, 1,069 panel members received a questionnaire by post and 1,747 through the internet. Panel members were free to answer the questions. They did not have to fill out all the questions; they were able to skip a question if they could not answer that specific question. One postal reminder (after 2 weeks) and two electronic reminders (after 1 and 2 weeks) were sent to panel members who had not yet responded. After 4 weeks, the questionnaire had been returned by 1,310 panel members (response rate $47 \%$ ).

\section{Data protection NIVEL-PCD and Dutch Health Care Consumer Panel}

Dutch law permits, under certain conditions, the use of extracts from electronic health records for research purposes. According to Dutch legislation, neither obtaining informed consent nor approval by a medical ethics committee is obligatory for this kind of observational study containing no directly identifiable data. ${ }^{36}$ With respect to NIVEL-PCD, participating general practices were contractually obliged to inform their patients about their participation in the NIVEL-PCD, and to inform patients about the possibility of opting out if they objected to their data being included in the database. This study has been approved by the governance bodies applicable to the NIVEL-PCD under nr. NZR-00315.069. The data from the Dutch Health Care Consumer Panel are processed anonymously and the data collection is registered with the Dutch Data Protection Authority (nr. 1262949). In addition, a privacy regulation applies to the consumer panel in general, as well as for the recruitment of patients via general practices participating in the NIVEL-PCD. According to Dutch legislation, neither obtaining informed consent nor approval by a medical ethics committee is obligatory for carrying out research through the panel. ${ }^{36}$ All panel members included in this study gave written informed consent to combine their answers from the questionnaires with the data about their use of health care, as registered by their GP participating in the NIVEL-PCD. For the present study, data from the NIVELPCD and the questionnaire were linked by an employee of NIVEL who is not working for either the NIVEL-PCD, or the Dutch Health Care Consumer Panel. In the resulting research file patients were marked with a random ID specific to the project in order to guarantee patients' privacy.

\section{Study sample}

The study sample consisted of the respondents to the questionnaire, who contacted their GP in 2015 for acute cough, acute rhinosinusitis, or urinary tract infection according to the NIVEL-PCD (Table 1 shows the ICPC-codes which were included). If there were patients with multiple relevant episodes then one episode was selected randomly.

\section{Measurements}

\section{Antibiotics prescription (dependent variable)}

The prescription data from the NIVEL-PCD were used to determine whether or not antibiotics were prescribed by the GP for each episode of illness selected. All prescriptions from the ATC subgroup J01 (antibacterials for systemic use) were included and were assigned to illness episodes based on the prescription dates and prescription ICPCs. The variable "antibiotics prescription" was coded as $0=$ no prescription for antibiotics, $1=$ prescription for antibiotics.

\section{Antibiotics indication (independent variable)}

The NIVEL-PCD data were used to determine the indication for antibiotics. For each episode of illness selected, the indication for antibiotics was estimated according to the definitions in Table 1. Patients' age, sex, morbidity data, test results, and prescription data were used to estimate 
whether antibiotics were indicated, not indicated, or could be considered ("unsure" indication) for each illness episode. The variable "antibiotics indication" was coded as $0=$ an indication for antibiotics, $1=$ antibiotics could be considered ("unsure" indication), and $2=$ no indication for antibiotics.

\section{Patient preferences (independent variable)}

Patient preferences for antibiotics were assessed in the questionnaire of the consumer panel (Figure S1). We defined patient preferences as preferences that were explicitly expressed; that is asking for an antibiotic prescription. They were measured using the question: "When you contacted your GP regarding your [acute cough, acute rhinosinusitis, or urinary tract infection], did you ask the GP for a prescription for an antibiotic?" Answer options were: 1) not at all; 2) actually not; 3) actually, and; 4) totally. For patients who answered in the questionnaire that they had not contacted their GP in 2015 for acute cough, acute rhinosinusitis, or urinary tract infection, more general preferences were used. These were assessed using the question: "If you were to have an [acute cough, acute rhinosinusitis, or urinary tract infection] then to what extent would you be inclined to ask the GP for an antibiotic prescription?" The answer options were the same. The answer options were recoded into two categories "preference for antibiotics" (coded as 1, actually and totally) and "no preference for antibiotics" (coded as 0 , not at all and actually not).

\section{Statistical analyses}

In the first instance, descriptive statistics were performed in order to gain insight into patient preferences for antibiotics, the indication for antibiotics, and the GP's prescription of antibiotics. Secondly, a logistic multilevel regression analysis was performed in order to test the role of patient preferences in the GP's prescription of an antibiotic. The model contained two levels as the data are structured hierarchically, with patients nested in general practices. A multilevel analysis took into account the nested structure of the data as well as the differences in the number of patients per practice. We included the GP's prescription of antibiotics as a dependent variable, and patient preferences and indication for antibiotics as independent variables. To examine whether the role of patient preferences is modified by the indication for antibiotics, an interaction effect between patient preferences and indication was included in the model. In the multilevel analysis, categorical variables (such as the indication for antibiotics) were recoded into dummy variables. All analyses were performed using STATA, version 14.0.

\section{Results Descriptive statistics}

According to data registered in the NIVEL-PCD, 286 respondents to the questionnaire contacted their GP in 2015 for acute cough $(38 \%, \mathrm{~N}=109)$, acute rhinosinusitis $(25 \%$, $\mathrm{N}=72)$ or urinary tract infections $(37 \%, \mathrm{~N}=105)$ (Table 2). The number of patients per practice ranged from $\mathrm{N}=5$ to $\mathrm{N}=44$ (data not shown). In half $(50 \%, \mathrm{~N}=144)$ of the cases prescribing antibiotics could be considered. In $17 \%(\mathrm{~N}=48)$ of the cases there was an indication for antibiotics, whereas there was no indication for antibiotics in 33\% (N=94) of the cases (Table 2). In $42 \%(\mathrm{~N}=120)$ of the cases the GP did indeed prescribe antibiotics. Where there was an indication for antibiotics, the GP prescribed them in $81 \%(\mathrm{~N}=39)$ of the cases; if the indication for antibiotics was "unsure" - that is when antibiotics can be considered - then the GP prescribed them in $38 \%(\mathrm{~N}=55)$ of the cases. Where there was no indication for antibiotics, the GP prescribed them in $28 \%(\mathrm{~N}=26)$ of the cases (data not shown). One out of five $(21 \%, N=50)$ patients stated that they asked, or would ask, for an antibiotic prescription when contacting their GP (Table 2). In half of these cases $(50 \%, \mathrm{~N}=25)$ the GP did indeed prescribe an antibiotic (data not shown).

\section{The role of patient preferences in the GP's prescription of antibiotics}

Table 3 shows that the indication for antibiotics is significantly associated with the GP's prescribing of them. GPs more often

Table 2 Results of descriptive statistics

\begin{tabular}{|c|c|c|c|c|}
\hline & Data source & $\mathbf{N}$ & $\mathbf{N}$ & $\%$ \\
\hline $\begin{array}{l}\text { Number of patients who } \\
\text { contacted their GP in } 2015 \text { for... }\end{array}$ & NIVEL-PCD & 286 & & \\
\hline Acute cough & & & 109 & 38.1 \\
\hline Acute rhinosinusitis & & & 72 & 25.2 \\
\hline Urinary tract infections & & & 105 & 36.7 \\
\hline Antibiotics prescribed by GP & NIVEL-PCD & 286 & & \\
\hline Yes & & & 120 & 42.0 \\
\hline No & & & 166 & 58.0 \\
\hline Indication for antibiotics ${ }^{\mathrm{a}}$ & NIVEL-PCD & 286 & & \\
\hline Yes & & & 48 & 16.7 \\
\hline $\begin{array}{l}\text { "Unsure" (ie, antibiotics can be } \\
\text { considered) }\end{array}$ & & & 144 & 50.4 \\
\hline No & & & 94 & 32.9 \\
\hline Patient preference for antibiotics & Consumer panel & 240 & & \\
\hline Yes & & & 50 & 20.8 \\
\hline No & & & 190 & 79.2 \\
\hline
\end{tabular}

Note: ${ }^{\text {a Based on the recommendations in the three guidelines (see Table I for }}$ extensive recommendations).

Abbreviations: GP, general practitioner; PCD, Primary Care Database; NIVEL, Netherlands Institute for Health Services Research. 
Table 3 Results of logistic multilevel regression analysis to examine the relationship between patient preferences and the GP's prescription of antibiotics ( $\mathrm{N}=240)$

\begin{tabular}{|c|c|c|c|}
\hline $\begin{array}{l}\text { GP's prescription of } \\
\text { antibiotics }(\mathrm{I}=\mathrm{Yes}, 0=\mathrm{No})\end{array}$ & $\begin{array}{l}\text { Odds } \\
\text { ratio }\end{array}$ & $95 \% \mathrm{Cl}$ & p-value \\
\hline \multicolumn{4}{|l|}{ Indication for antibiotics ${ }^{\mathrm{a}}$} \\
\hline Yes & Reference & Reference & Reference \\
\hline $\begin{array}{l}\text { "Unsure" (ie, antibiotics can } \\
\text { be considered) }\end{array}$ & 0.067 & $0.018-0.245$ & 0.000 \\
\hline No & 0.053 & $0.014-0.203$ & 0.000 \\
\hline \multicolumn{4}{|l|}{ Patient preference for antibiotics } \\
\hline No & Reference & Reference & Reference \\
\hline Yes & 0.401 & $0.067-2.411$ & 0.318 \\
\hline \multicolumn{4}{|c|}{ Patient preference for antibiotics \# indication for antibiotics } \\
\hline $\begin{array}{l}\text { Preference No and } \\
\text { indication Yes }\end{array}$ & Reference & Reference & Reference \\
\hline $\begin{array}{l}\text { Preference Yes and } \\
\text { indication "Unsure" }\end{array}$ & 7.696 & $1.009-58.679$ & 0.049 \\
\hline $\begin{array}{l}\text { Preference Yes and } \\
\text { indication No }\end{array}$ & 0.973 & $0.087-10.85 \mid$ & 0.982 \\
\hline Constant & 7.558 & $2.224-25.683$ & 0.001 \\
\hline
\end{tabular}

Notes: a Based on the recommendations in the three guidelines (see Table I for extensive recommendations). "The interaction effect between preference and indication was tested. Bold type indicates $p<0.05$.

Abbreviation: GP, general practitioner.

prescribe antibiotics in cases with an indication for antibiotics compared to cases in which antibiotics can be considered and in cases with no indication for antibiotics. No significant association was found between patient preferences and the GP's prescribing of antibiotics. However, the interaction effect between indication and patient preferences was significant $(p=0.049)$. The results indicate that the relationship between patient preferences and the GP's prescribing of antibiotics varies according to the indication for antibiotics. Patient preferences have a role in the GP's prescribing of antibiotics in situations where, according to the guideline, antibiotics can be considered; that is that there is an "unsure" indication. If in such situations patients ask for antibiotics then GPs will more often prescribe them.

\section{Discussion}

This study sought to achieve insight into the potential conflict in making medical decisions regarding the prescription of antibiotics by GPs. On the one hand GPs should apply the guidelines and on the other include their patient preferences. Our results show that there is no real conflict. The reason for this is that in cases where the guideline provides a clear recommendation to prescribe or not, we did not find a significant relationship between patient preferences and the GP's decision to prescribe antibiotics. Patient preferences appear only to play a role in the GP's decision if prescribing an antibiotic was an option that could be considered. However, in those situations there is no conflict between applying the guidelines and including patient preferences. In such situations, antibiotics are justified since the guideline provides room for taking patient preferences into account.

This study has been performed in the Netherlands, a country with comparatively low and stable antibiotic use in primary care. ${ }^{17,22}$ Furthermore, around nine out of ten Dutch people agree that bacteria can become less susceptible (resistant) to antibiotics ${ }^{37}$ and that prescribing antibiotics for minor ailments is not necessary. ${ }^{24}$ It might be that in countries with a higher antibiotic use, patient preferences do play a role in the GP's decision to prescribe antibiotics, even if the guideline provides a clear recommendation not to prescribe them. Moreover, this study focused on just one type of decision: the prescription of antibiotics by GPs. Further research is recommended into whether, in other situations, there is a conflict between applying the guidelines and including patient preferences. Patient preferences may play a role in the failure to adhere to guidelines in other situations.

Although including patient preferences in medical decision-making is regarded as an indicator of good quality of care, ${ }^{12}$ it could be questioned whether patient preferences have to play a role in all situations. In some situations, there is one treatment, which on the basis of reasonably sound medical evidence is known to work better than any alternative, and for which the benefits of treatment exceed the side effects or unintended consequences (ie, effective care). As such, in general, all eligible patients have to receive that treatment. ${ }^{38}$ It has to be recognized, however, that also in situations of effective care patients have a choice, even if it is not wanting treatment. An example of effective care in the context of this study is that antibiotics are always indicated for men in the case of urinary tract infections (Table 1) and thus, in general, they have to receive an antibiotic prescription.

Preferences are more likely to play a role if there is no absolute best treatment option. For this so-called preferencesensitive care the right treatment for an individual patient should depend on the patient's preference..$^{38}$ An example in the context of this study is that antibiotics can be considered for otherwise healthy women with urinary tract infections who are not pregnant (Table 1). In the case of preferencesensitive care, however, professional judgments rather than patients' own preferences often determine which treatment a patient receives. The reason for this is that patients often delegate medical decision-making to their physician. ${ }^{38}$ Also, in the context of antibiotics, it has been argued that clinicians, on their own, do not know whether or not antibiotics are best for individual patients; clinicians commonly misinterpret 
patients' expectations of antibiotic treatment. ${ }^{39}$ An approach which promotes the uptake of patient preferences in the decision-making process, is shared decision-making (SDM). Here, physicians and patients make decisions together using the best available evidence. Patients are helped to make informed choices by considering each option and its possible benefits and disadvantages. ${ }^{40,41}$ Well-informed patients are known to prefer more conservative treatment options. ${ }^{42}$ In the context of this study, this would mean not using antibiotics. SDM has been recognized as a framework for enhancing the appropriate use of antibiotics and hence for controlling resistance to antibiotics. ${ }^{39,43}$ Research showed that SDM reduces antibiotic prescribing rates for acute respiratory infections in primary care ${ }^{44}$ Furthermore, it has been reasoned that SDM results in fewer inappropriate demands for antibiotics in the future. ${ }^{43}$

A strength of this study is that we combined data about patient preferences for antibiotics and the GP's prescription of antibiotics at the level of the patient. Moreover, we could individually estimate the indication for antibiotics using the NIVEL-PCD. We only found one other study which directly combined patient views about antibiotics with the antibiotic prescribing behavior of GPs. ${ }^{30}$ Coenen et al collected data in 13 different European countries and found that a patient's expectations and hopes were positively associated with antibiotic prescribing by GPs for acute cough. They did not find an association with asking for antibiotics. ${ }^{30}$ However, they focused solely on acute cough and did not examine whether the role of the patient's views differed according to the indication for antibiotics. Another strength is that we took into account the nested structure of our data by performing a multilevel analysis. However, from the data set, it was only possible to know at which general practice a patient had a consultation, but not with which GP within that general practice. Earlier research shows that Dutch GPs working in the same practice show more similarity in their attitudes and behavior than GPs who do not work in the same practice. ${ }^{45}$ Therefore, we do not expect this to affect our conclusions. Although we had a large sample size $(\mathrm{N}=1,310)$, a potential limitation is the relatively low response rate of $47 \%$. A multidisciplinary research team including experts in the field of antibiotics developed the questionnaire. The draft questionnaire was also commented upon by the program committee of the Dutch Health Care Consumer Panel, consisting of representatives of different actors in the health care sector, including the Dutch Ministry of Health, Welfare and Sport, the Dutch Consumers Association, and the Dutch
Health Care Inspectorate. Nevertheless, a limitation is that the questionnaire has not been tested in a pilot study among panel members. It is therefore debatable whether all questions and answer options were sufficiently clear for the panel members. Another limitation of the present study is the recall bias of the respondents to the questionnaire. Not all respondents answered in the questionnaire that they had contacted their GP in 2015 for acute cough, acute rhinosinusitis or urinary tract infections. As such, for this part $(\mathrm{N}=149)$, the patients' preference, in general, for antibiotics was used. Furthermore, if patients remember that they had contacted their GP, we do not know whether this necessarily refers to the same contact as that in the NIVEL-PCD. Another limitation is that we defined preferences as those preferences which were expressed explicitly; that is asking for an antibiotic prescription. We did not consider preferences which were not explicitly expressed, nor the option to state to prefer not to have an antibiotic prescription. In addition, we did not study whether groups of patients differ in their preferences for antibiotics. It can be reasoned that patients differ in their ability to ask their physician for an antibiotic prescription. ${ }^{46}$ Further research is recommended to examine possible differences between groups of patients.

The results of this study do not suggest a conflict between applying guidelines and including patient preferences in medical decision making in the case of antibiotics prescribing by Dutch GPs. Further research is recommended to examine whether this conflict exists in other decision-making situations.

\section{Acknowledgment}

The study was partially supported by The National Health Care Institute of the Netherlands, within the cooperative framework that NIVEL and The National Health Care Institute had together.

\section{Disclosure}

LVD received funding from Bristol-Myers Squibb, Abbvie, Pfizer, and Astra Zeneca for projects not related to this project. She received funding from the European Commission as well as from The National Health Care Institute of the Netherlands for studies into the prudent use of antibiotics in the European Union and the Netherlands, respectively. TEMVE and KH received funding from The National Health Care Institute of the Netherlands for a study into the prudent use of antibiotics in the Netherlands. The authors report no other conflicts of interest in this work. 


\section{References}

1. Graham R, Mancher M, Wolman DM, Greenfield S, Steinberg E. Clinical practice guidelines we can trust. National Academies Press; 2011.

2. Grimshaw JM, Russell IT. Effect of clinical guidelines on medical practice: a systematic review of rigorous evaluations. Lancet. 1993; 342(8883):1317-1322.

3. Woolf SH, Grol R, Hutchinson A, Eccles M, Grimshaw J. Clinical guidelines: potential benefits, limitations, and harms of clinical guidelines. BMJ. 1999;318(7182):527-530.

4. Grilli R, Magrini N, Penna A, Mura G, Liberati A. Practice guidelines developed by specialty societies: the need for a critical appraisal. Lancet. 2000;355(9198):103-106

5. Mainz J. Defining and classifying clinical indicators for quality improvement. Int J Qual Health Care. 2003;15(6):523-530.

6. de Jong JD, Groenewegen PP, Spreeuwenberg P, Schellevis F, Westert GP. Do guidelines create uniformity in medical practice? Soc Sci Med. 2010;70(2):209-216.

7. van Dijk L, de Jong JD, Westert GP, de Bakker DH. Variation in formulary adherence in general practice over time (2003-2007). Fam Pract. 2011;28(6):624-631.

8. Ivanovska V, Hek K, Mantel Teeuwisse AK, Leufkens HG, Nielen MM, van Dijk L. Antibiotic prescribing for children in primary care and adherence to treatment guidelines. J Antimicrob Chemother. 2016;71(6): 1707-1714.

9. Braspenning J, Schellevis F, Grol R. Tweede Nationale Studie naar ziekten en verrichtingen in de huisartspraktijk: kwaliteit huisartsenzorg belicht. [Second Dutch National Survey of General Practice. Focus on Quality of General Practice Care]. Utrecht/Nijmegen: NIVEL/WOK; 2004. Dutch.

10. van den Berg MJ, de Bakker DH, Spreeuwenberg P, Westert GP, Braspenning JC, van der Zee J, Groenewegen PP. Labour intensity of guidelines may have a greater effect on adherence than GPs' workload. BMC Fam Pract. 2009;10(1):74.

11. Lugtenberg M, Burgers JS, Besters CF, Han D, Westert GP. Perceived barriers to guideline adherence: a survey among general practitioners. BMC Fam Pract. 2011;12:98.

12. Institute of Medicine. Crossing the quality chasm: A new health system for the 21st century. National Academies Press; 2001.

13. Greer AL, Goodwin JS, Freeman JL, Wu ZH. Bringing the patient back in. Guidelines, practice variations, and the social context of medical practice. Int J Technol Assess Health Care. 2002;18(4):747-761.

14. Krahn M, Naglie G. The next step in guideline development: incorporating patient preferences. JAMA. 2008;300(4):436-438.

15. Butler CC, Hood K, Verheij T, et al. Variation in antibiotic prescribing and its impact on recovery in patients with acute cough in primary care: prospective study in 13 countries. BMJ. 2009;338:b2242.

16. Cordoba G, Siersma V, Lopez-Valcarcel B, Bjerrum L, Llor C, Aabenhus R, Makela M. Prescribing style and variation in antibiotic prescriptions for sore throat: cross-sectional study across six countries. BMC Fam Pract. 2015;16(1):7.

17. Goossens H, Ferech M, Vander Stichele R, Elseviers M; ESAC Project Group. Outpatient antibiotic use in Europe and association with resistance: a cross-national database study. Lancet. 2005;365(9459): 579-587.

18. van Bijnen EM, Paget J, de Lange-de Klerk ES, et al. Antibiotic exposure and other risk factors for antimicrobial resistance in nasal commensal Staphylococcus aureus: an ecological study in 8 European countries. PLoS One. 2015;10(8):e0135094.

19. Riedel S, Beekmann SE, Heilmann KP, et al. Antimicrobial use in Europe and antimicrobial resistance in Streptococcus pneumoniae. Eur J Clin Microbiol Infect Dis. 2007;26(7):485-490.

20. WHO. Antimicrobial resistance: 2014 global report on surveillance. World Health Organization; 2014. Available from http://apps.who. int/iris/bitstream/10665/112642/1/9789241564748_eng.pdf. Accessed December 5, 2017.
21. Cecchini M, Langer J, Slawomirski L. Antimicrobial Resistance in G7 Countries and Beyond: Economic Issues, Policies and Options for Action. Paris: Organization for Economic Co-operation and Development; 2015. Available from https:/www.oecd.org/els/health-systems/ Antimicrobial-Resistance-in-G7-Countries-and-Beyond.pdf. Accessed December 5, 2017.

22. Adriaenssens N, Coenen S, Versporten A, et al. European Surveillance of Antimicrobial Consumption (ESAC): outpatient antibiotic use in Europe (1997-2009). J Antimicrob Chemother. 2011;66 Suppl 6: vi3-vi12.

23. van Bergeijk H, Berger M. Behandeling van urineweginfecties binnen en buiten praktijkuren. [Treatment of urinary tract infections in and out of hours]. Huisarts en Wetenschap. 2008;51(9):430-434. Dutch.

24. Van Esch T, Mullenders P, Brabers A, Hek K, De Jong J. De rol van patiënten bij het afwijken van richtlijnen door huisartsen: een onderzoek naar het voorschrijven van antibiotica. [The role of patients in non-adherence to guidelines by general practitioners in prescribing antibiotics]. Utrecht: NIVEL; 2016. Dutch.

25. Van Esch T, Van Dijk L, Weesie Y, et al. Antibioticagebruik bij luchtweginfecties in de eerste lijn. [Antibiotic use for respiratory tract infections in primary care]. Utrecht: NIVEL; 2016. Dutch.

26. Coenen S, Michiels B, Renard D, Denekens J, Van Royen P. Antibiotic prescribing for acute cough: the effect of perceived patient demand. Br J Gen Pract. 2006;56(524):183-190.

27. Butler CC, Rollnick S, Pill R, Maggs-Rapport F, Stott N. Understanding the culture of prescribing: qualitative study of general practitioners' and patients' perceptions of antibiotics for sore throats. BMJ. 1998; 317(7159):637-642.

28. Macfarlane J, Holmes W, Macfarlane R, Britten N. Influence of patients' expectations on antibiotic management of acute lower respiratory tract illness in general practice: questionnaire study. BMJ. 1997;315(7117): 1211-1214.

29. Britten N, Ukoumunne O. The influence of patients' hopes of receiving a prescription on doctors' perceptions and the decision to prescribe: a questionnaire survey. BMJ. 1997;315(7121):1506-1510.

30. Coenen S, Francis N, Kelly M, et al. Are patient views about antibiotics related to clinician perceptions, management and outcome? A multi-country study in outpatients with acute cough. PLoS One. 2013; 8(10): 76691

31. NIVEL [database on the Internet]. Utrecht: NIVEL Primary Care Database. Available from: http://www.nivel.nl/en/nivel-primary-caredatabase. Accessed November 8, 2017.

32. Hofmans-Okkes IM, Lamberts H. The International Classification of Primary Care (ICPC): new applications in research and computerbased patient records in family practice. Fam Pract. 1996;13(3): 294-302.

33. Lambert H, Woods M. The International Classification of Primary Care (ICPC): Oxford: Oxford University Press; 1987.

34. Nielen M, Spronk I, Davids R, et al. A new method for estimating morbidity rates based on routine electronic medical records in primary care. 21st WONCA Europe Conference 15-18 June 2016. Kopenhagen; 2016.

35. Brabers A, Reitsma-van Rooijen M, De Jong J. Consumentenpanel Gezondheidszorg: basisrapport met informatie over het panel (2015). [Dutch Health Care Consumer Panel: report with information about the panel (2015)]. Utrecht: NIVEL; 2015.

36. ccmo.nl [homepage on the Internet]. Your research: does it fall under the WMO? The Hague: CCMO. Available from: http://www. ccmo.nl/en/your-research-does-it-fall-under-the-wmo. Accessed November 8, 2017.

37. Cals JW, Boumans D, Lardinois RJ, Gonzales R, Hopstaken RM, Butler CC, Dinant GJ. Public beliefs on antibiotics and respiratory tract infections: an internet-based questionnaire study. Br J Gen Pract. 2007;57(545):942-947.

38. Wennberg JE. Tracking medicine: a researcher's quest to understand health care. Oxford: Oxford University Press; 2010. 
39. Butler CC, Kinnersley P, Prout H, Rollnick S, Edwards A, Elwyn G. Antibiotics and shared decision-making in primary care. J Antimicrob Chemother. 2001;48(3):435-440.

40. Elwyn G, Laitner S, Coulter A, Walker E, Watson P, Thomson R. Implementing shared decision making in the NHS. BMJ. 2010; 341:c5146.

41. Elwyn G, Frosch D, Thomson R, et al. Shared decision making: a model for clinical practice. J Gen Intern Med. 2012; 27(10):1361-1367.

42. Stacey D, Bennett CL, Barry MJ, et al. Decision aids for people facing health treatment or screening decisions. Cochrane Database Syst Rev. 2011;(10):CD001431.

43. Davey P, Pagliari C, Hayes A. The patient's role in the spread and control of bacterial resistance to antibiotics. Clin Microbiol Infect. 2002; 8 Suppl 2:43-68.

44. Coxeter P, Del Mar CB, McGregor L, Beller EM, Hoffmann TC. Interventions to facilitate shared decision making to address antibiotic use for acute respiratory infections in primary care. Cochrane Database Syst Rev. 2015;(11):CD010907.

45. de Jong JD, Groenewegen PP, Westert GP. Mutual influences of general practitioners in partnerships. Soc Sci Med. 2003;57(8):1515-1524.
46. Hajjaj FM, Salek MS, Basra MK, Finlay AY. Non-clinical influences on clinical decision-making: a major challenge to evidence-based practice. J R Soc Med. 2010;103(5):178-187.

47. NHG. Handleiding. Ontwikkelen van NHG-Standaarden. [Development of NHG-guidelines]. Utrecht: NHG, 2015

48. NHG. Richtlijnen en praktijk. [Guidelines and practice]. [webpage on the Internet]. Available at: https://www.nhg. org/richtlijnen-praktijk. Accessed October 20, 2016.

49. Nederlands huisartsen genootschap. Acuut hoesten. [Acute coughing]. [webpage on the Internet]. Available from https:/www.nhg.org/ standaarden/samenvatting/acuut-hoesten. Accessed December 5, 2017. Dutch.

50. Nederlands huisartsen genootschap. Acuut rhinosinusitis. [Acute rhinosinusitis]. [webpage on the Internet]. https://www.nhg.org/ standaarden/samenvatting/acute-rhinosinusitis. Accessed December 5, 2017. Dutch.

51. Nederlands huisartsen genootschap. Urineweginfecties. [Urinary tract infections]. [webpage on the Internet]. https://www.nhg.org/ standaarden/samenvatting/urineweginfecties. Accessed December 5, 2017. Dutch. 


\section{Supplementary material}

ACUTE COUGH (cough symptoms that last less than three weeks)

The next question is about the contact with your general practitioner regarding your acute cough. Please answer the next question regarding the last time in $\mathbf{2 0 1 5}$ that you contacted your general practitioner for acute cough for yourself.

When you contacted your general practitioner regarding your acute cough...

\begin{tabular}{|lllll}
\hline & Not at all & Actually not & Actually & Totally \\
\hline Did you ask the general practitioner for a prescription for an antibiotic? & $\square$ & $\square$ & $\square$ & $\square$ \\
\hline
\end{tabular}

ACUTE RHINOSINUSITIS (when you have acute rhinosinusitis, you have, besides a runny or stuffy nose, additional symptoms like feeling pain/pressure in your face or smelling less well)

The next question is about the contact you had with your general practitioner regarding your acute rhinosinusitis. Please answer the next question regarding the last time in $\mathbf{2 0 1 5}$ that you contacted your general practitioner for acute rhinosinusitis for yourself.

When you contacted your general practitioner regarding your acute rhinosinusitis...

\begin{tabular}{|c|c|c|c|c|}
\hline & Not at all & Actually not & Actually & Totally \\
\hline Did you ask the general practitioner for a prescription for an antibiotic? & $\square$ & 口 & 口 & 口 \\
\hline
\end{tabular}

URINARY TRACT INFECTION (symptoms of a urinary tract infection are: painful urination, frequently urinate a little bit, pain in your back or abdomen)

The next question is about the contact you had with your general practitioner regarding your urinary tract infection. Please answer the next question regarding the last time in $\mathbf{2 0 1 5}$ that you contacted your general practitioner for urinary tract infection for yourself. When you contacted your general practitioner regarding your urinary tract infection...

\begin{tabular}{|c|c|c|c|c|}
\hline & Not at all & Actually not & Actually & Totally \\
\hline Did you ask the general practitioner for a prescription for an antibiotic? & $\square$ & 口 & $\square$ & $\square$ \\
\hline
\end{tabular}

\section{VIEWS ON ANTIBIOTICS}

The next questions are about your views on antibiotics in general. We ask everyone to fill out the questions, even if you did not have symptoms. We ask you to imagine that the described situation applies to you.

If you were to have an acute cough. This is about cough symptoms that last less than three weeks. To what extent...

\begin{tabular}{|lllll}
\hline & Not at all & Actually not & Actually & Totally \\
\hline Would you be inclined to ask the general practitioner for an antibiotic prescription? & $\square$ & $\square$ & $\square$ & $\square$
\end{tabular}

If you were to have acute rhinosinusitis. When you have acute rhinosinusitis, you have, besides a runny or stuffy nose, additional symptoms like feeling pain/pressure in your face or smelling less well. To what extent...

\begin{tabular}{|lllll}
\hline & Not at all & Actually not & Actually & Totally \\
\hline Would you be inclined to ask the general practitioner for an antibiotic prescription? & $\square$ & $\square$ & $\square$ & $\square$ \\
\hline
\end{tabular}

If you were to have a urinary tract infection. Symptoms of a urinary tract infection are: painful urination, frequently urinate a little bit, pain in your back or abdomen. To what extent...

\begin{tabular}{|c|c|c|c|c|}
\hline & Not at all & Actually not & Actually & Totally \\
\hline Would you be inclined to ask the general practitioner for an antibiotic prescription? & a & a & a & $\square$ \\
\hline
\end{tabular}

Figure SI Patient questionnaire on preferences for antibiotic prescribing. Questionnaire sent to members of the Dutch Health Care Consumer Panel (translated to English). 


\section{Publish your work in this journal}

Patient Preference and Adherence is an international, peer-reviewed, open access journal that focuses on the growing importance of patient preference and adherence throughout the therapeutic continuum. Patient satisfaction, acceptability, quality of life, compliance, persistence and their role in developing new therapeutic modalities and compounds to optimize

Submit your manuscript here: http://www.dovepress.com/patient-preference-and-adherence-journ clinical outcomes for existing disease states are major areas of interest for the journal. This journal has been accepted for indexing on PubMed Central The manuscript management system is completely online and includes a very quick and fair peer-review system, which is all easy to use. Visit http://www. dovepress.com/testimonials.php to read real quotes from published authors. 